\title{
Management of patients with early stage lung cancer - why do some patients not receive treatment with curative intent?
}

Ross Lawrenson ${ }^{1,2^{*}}$, Chunhuan Lao', Leonie Brown', Lucia Moosa ${ }^{3}$, Lynne Chepulis', Rawiri Keenan', Jacquie Kidd', Karen Middleton ${ }^{5}$, Paul Conaglen ${ }^{6}$, Charles de Groot ${ }^{7}$, Denise Aitken ${ }^{8}$ and Janice Wong ${ }^{5}$

\begin{abstract}
Backgrounds: This study aims to understand the factors that influence whether patients receive potentially curative treatment for early stage lung cancer. A key question was whether indigenous Māori patients were less likely to receive treatment.

Methods: Patients included those diagnosed with early stage lung cancer in 2011-2018 and resident in the New Zealand Midland Cancer Network region. Logistic regression model was used to estimate the odds ratios of having curative surgery/ treatment. The Kaplan Meier method was used to examine the all-cause survival and Cox proportional hazard model was used to estimate the hazard ratio of death.

Results: In total 419/583 (71.9\%) of patients with Stage I and II disease were treated with curative intent - 272 (46.7\%) patients had curative surgery. Patients not receiving potentially curative treatment were older, were less likely to have non-small cell lung cancer (NSCLC), had poorer lung function and were more likely to have an ECOG performance status of 2+. Current smokers were less likely to be treated with surgery and more likely to receive treatment with radiotherapy and chemotherapy. Those who were treated with surgery had a 2-year survival of $87.8 \%$ (95\% Cl: 83.8$91.8 \%)$ and 5-year survival of $69.6 \%$ (95\% Cl: 63.2-76.0\%). Stereotactic ablative body radiotherapy (SABR) has equivalent effect on survival compared to curative surgery (hazard ratio: $0.77,95 \% \mathrm{Cl}: 0.37-1.61$ ). After adjustment we could find no difference in treatment and survival between Māori and non-Māori.

Conclusions: The majority of patients with stage I and II lung cancer are managed with potentially curative treatment - mainly surgery and increasingly with SABR. The outcomes of those being diagnosed with stage I and II disease and receiving treatment is positive with $70 \%$ surviving 5 years.
\end{abstract}

Keywords: Lung cancer, Non-small cell lung cancer, Thoracic surgery, Stereotactic ablative body radiotherapy, Smoking

\section{Background}

Lung cancer is the leading cause of cancer death in New Zealand [1]. Mortality in Māori, the indigenous people in New Zealand, is 2.6 times greater than in New Zealand Europeans [1]. Overall, outcomes from lung cancer in New Zealand are poor with a 5-year survival of only $11 \%$ [2]. This is mainly because the majority of lung cancer patients are diagnosed at late stage. In a recent study of lung

\footnotetext{
* Correspondence: Ross.Lawrenson@waikatodhb.health.nz

'Waikato Medical Research Centre, The University of Waikato, Level 3 Hockin building, Waikato Hospital, Hamilton 3240, New Zealand

${ }^{2}$ Strategy and Funding, Waikato District Health Board, Hamilton, New

Zealand

Full list of author information is available at the end of the article
}

cancer patients in our New Zealand region, only $16.5 \%$ were diagnosed with early stage (stage I and II) lung cancer [3].

Patients with early stage disease can be considered curable with successful surgery, or stereotactic ablative body radiotherapy (SABR) [4]. Some stage II and III patients also have successful outcomes with radical radiotherapy and chemo radiotherapy. Surgical resection rates for lung cancer vary between countries and even between centres in a particular country [5]. Overall, $14.7 \%$ of non-small cell lung cancer (NSCLC) patients receive surgery in New Zealand compared to $19.1 \%$ in Victoria, Australia [6, 7]. Previous studies in New Zealand have reported lower

(C) The Author(s). 2020 Open Access This article is distributed under the terms of the Creative Commons Attribution 4.0 International License (http://creativecommons.org/licenses/by/4.0/), which permits unrestricted use, distribution, and 
surgical rates in Māori [8]. New Zealand is looking to improve the proportion of lung cancer patients diagnosed with early stage through the use of an educational campaign. However, we have limited data on how early stage lung cancer is currently managed? There are also limited data on the outcomes of treatment of early stage disease.

The Midland Lung Cancer Register collects data from four District Health Boards (DHB) with a combined population of 800,000 residents. Tertiary lung cancer management is principally based at Waikato Hospital [3]. Waikato Hospital provides both surgical services and radiotherapy services for cancer patients for the region; with radiotherapy services also available in the Bay of Plenty DHB. This study aims to understand the factors that influence whether patients receive potentially curative treatment for their lung cancer, to understand which patients receive surgical management, and to examine the outcomes in those receiving surgery, other forms of treatment compared to those patients who receive palliative care.

\section{Methods}

We analysed lung cancer data from the Midland Lung Cancer Register between January 2011 and December 2018 [3]. The Midland Lung Cancer Register is derived from data collected at multidisciplinary meetings (MDMs) within the region and complemented by data sourced from the New Zealand Cancer Registry (NZCR). Patients diagnosed with stage I and II lung cancer (ICD code: C33, C34) and resident in the Midland Cancer Network region (including Waikato, Lakes, Bay of Plenty and Tairawhiti District Health Board) in 2011-2018 were included. Patients that were not discussed at an MDM were identified by the NZCR, and missing data was included from examination of their clinical records. For those who did not have a record of treatment, patient notes were searched to ascertain the reasons for no treatment. These were categorised into: comorbidities, poor lung function, poor Eastern Cooperative Oncology Group (ECOG) performance status (2+) [9], high risk of surgical complications, patient refusal or unknown reasons.

Data collected on individual patients included age, sex, ethnicity, DHB of domicile, type of lung cancer (NSCLC, small cell, others and unknown), stage of cancer, lung function (FEV1 measurement), ECOG status, and presence of known co-morbidities as measured by Charlson Index [10]. We then identified the treatment received by patients, including curative surgery (lobectomy, partial resection of lung and pneumonectomy), curative radiotherapy (radical radiotherapy), SABR, curative chemo radiation or palliative treatment which could include palliative chemo radiation, palliative chemotherapy, or symptomatic palliative care only. Mortality data were derived from the Midland Lung Cancer Register, New Zealand Cancer Registry and hospital system (iPM) with a censor date of 25 June 2019. Statistical analyses were then performed on this Combined Lung Cancer Register.

In order to determine if there is an ethnic basis to inequity of care, patient demographics, tumour characteristics and treatment were compared between Māori and non-Māori patients. The difference was examined with Chi-square test. Reasons for not having potentially curative surgery as the primary treatment were also explored and classified into comorbidity, lung function problems, poor ECOG status, surgical complications, patient refusal and unknown/other reasons. Logistic regression model was used to estimate the odds ratios of having curative treatment for Māori patients compared with non-Māori patients after adjustment for patient demographics and tumour characteristics. We also examined the factors that influence whether patients received alternative curative treatment compared to surgery.

The Kaplan Meier method was used to examine the all-cause survival by treatment option and by ethnicity (Māori vs non-Māori). For survival analyses, patients without mortality information were considered to be censored on 25 June 2019. Cox proportional hazard model was used to estimate the hazard ratio of death for Māori compared to non-Māori after adjustment for age, sex, year of diagnosis, stage, comorbidities and treatments. All data analyses were performed in IBM SPSS statistics 25 (New York, United States).

\section{Results}

The Combined Lung Cancer Register included 3331 resident cases (1050 Māori and 2281 non-Māori) between 2011 and 2018. This study included 583/3331 (17.5\%) with early stage disease (Table 1 ). This was made up of 169/1050 (16.1\%) Māori and 414/2281 (18.1\%) non-Māori patients. Over $90 \%$ of the early stage patients were either a current smoker (30.9\%) or ex-smoker (60.1\%). Among the lung cancer patients, $47.7 \%$ had a history of chronic obstructive pulmonary disease (COPD). There were 452 cases of NSCLC, 14 cases of small cell lung cancer, and 106 patients did not have a pathology report. A record of unknown pathology was associated with significant comorbidities in 37 (34.9\%) patients, frailty/high risk - ECOG 2+ 10 (9.4\%) and very poor lung function 25 (23.6\%). The 169 Māori patients were younger, more likely to be current smokers, have a diagnosis of COPD and have NSCLC-other and small cell lung cancer, and more likely to have FEV1 of $<50 \%$ than non-Māori patients.

In total 419/583 (71.9\%) of patients with Stage I and II disease were treated with curative intent - $272(46.7 \%)$ patients had curative surgery, including 199 lobectomies, 59 partial resection of lung, and 14 pneumonectomy (Table 2). Another 64 (11.0\%) patients were treated with SABR, 67 (11.5\%) received curative radical radiotherapy, 
Table 1 Patient demographics and tumour characteristics

\begin{tabular}{|c|c|c|c|c|}
\hline Subgroup & Māori & Non-Māori & $P$-value (Chi-square test) & Total \\
\hline \multicolumn{5}{|l|}{ Sex } \\
\hline Female & $104(61.5 \%)$ & $220(53.1 \%)$ & \multirow[t]{2}{*}{0.064} & $324(55.6 \%)$ \\
\hline Male & 65 (38.5\%) & $194(46.9 \%)$ & & $259(44.4 \%)$ \\
\hline \multicolumn{5}{|l|}{ Age (years) } \\
\hline$<60$ & 35 (20.7\%) & $53(12.8 \%)$ & \multirow[t]{4}{*}{$<0.001$} & 88 (15.1\%) \\
\hline $60-69$ & 65 (38.5\%) & $120(29.0 \%)$ & & $185(31.7 \%)$ \\
\hline $70-79$ & 57 (33.7\%) & $170(41.1 \%)$ & & $227(38.9 \%)$ \\
\hline $80+$ & $12(7.1 \%)$ & $71(17.1 \%)$ & & $83(14.2 \%)$ \\
\hline \multicolumn{5}{|l|}{ Smoking status } \\
\hline Current smoker & $63(40.4 \%)$ & $104(27.0 \%)$ & \multirow[t]{4}{*}{$<0.001$} & $167(30.9 \%)$ \\
\hline Ex-smoker & 91 (58.3\%) & $234(60.8 \%)$ & & $325(60.1 \%)$ \\
\hline Never smoked & $2(1.3 \%)$ & $47(12.2 \%)$ & & 49 (9.1\%) \\
\hline Unknown & 13 & 29 & & 42 \\
\hline \multicolumn{5}{|c|}{ Charlson Comorbidity } \\
\hline 0 & 37 (21.9\%) & $119(28.7 \%)$ & \multirow[t]{5}{*}{$<0.001$} & $156(26.8 \%)$ \\
\hline 1 & $44(26.0 \%)$ & $147(35.5 \%)$ & & $191(32.8 \%)$ \\
\hline 2 & $51(30.2 \%)$ & 99 (23.9\%) & & $150(25.7 \%)$ \\
\hline 3 & 29 (17.2\%) & $33(8.0 \%)$ & & $62(10.6 \%)$ \\
\hline $4+$ & $8(4.7 \%)$ & $16(3.9 \%)$ & & $24(4.1 \%)$ \\
\hline \multicolumn{5}{|l|}{ COPD } \\
\hline No & 57 (39.9\%) & $207(57.2 \%)$ & \multirow[t]{3}{*}{$<0.001$} & $264(52.3 \%)$ \\
\hline Yes & $86(60.1 \%)$ & 155 (42.8\%) & & $241(47.7 \%)$ \\
\hline Unknown & 26 & 52 & & 78 \\
\hline \multicolumn{5}{|l|}{ Cell type } \\
\hline NSCLC & 124 (91.2\%) & 328 (96.2\%) & \multirow[t]{4}{*}{$<0.001$} & 452 (94.8\%) \\
\hline Others & $2(1.5 \%)$ & $9(2.6 \%)$ & & 11 (2.3\%) \\
\hline Small cell & $10(7.4 \%)$ & $4(1.2 \%)$ & & 14 (2.9\%) \\
\hline Unknown & 33 & 73 & & 106 \\
\hline \multicolumn{5}{|l|}{ FEV1 } \\
\hline$<50 \%$ & 46 (30.3\%) & 63 (17.4\%) & \multirow[t]{4}{*}{$<0.001$} & 109 (21.2\%) \\
\hline $50 \% \sim 80 \%$ & 70 (46.1\%) & 139 (38.4\%) & & 209 (40.7\%) \\
\hline $80 \%+$ & 36 (23.7\%) & 160 (44.2\%) & & 196 (38.1\%) \\
\hline Unknown & 17 & 52 & & 69 \\
\hline \multicolumn{5}{|l|}{ ECOG } \\
\hline 0 & $51(32.3 \%)$ & 157 (40.6\%) & \multirow[t]{5}{*}{0.194} & 208 (38.2\%) \\
\hline 1 & 73 (46.2\%) & 158 (40.8\%) & & 231 (42.4\%) \\
\hline $2+$ & 34 (21.5\%) & 72 (18.6\%) & & 106 (19.4\%) \\
\hline Unknown & 11 & 27 & & 38 \\
\hline Total & 169 & 414 & & 583 \\
\hline
\end{tabular}

and $16(2.7 \%)$ had curative chemo/radiotherapy. Amongst those not having curative treatment (164 (28.1\%)), 33 (5.7\%) had palliative radiotherapy, 14 (2.4\%) had palliative chemotherapy, and 117 (20.1\%) had best supportive care alone. Māori patients appeared to be less likely to have curative surgery $(39.6 \%$ vs $49.5 \%, p$-value $=0.027)$, but were as likely to have curative treatment as non-Māori patients $(70.4 \%$ vs $72.5 \%, p$-value $=0.618)$. The principal reason recorded in the patient records indicating why these lung cancer patients did not have curative treatment 
Table 2 Primary treatment for lung cancer patients by ethnicity

\begin{tabular}{llll}
\hline Primary treatment & Māori & Non-Māori & Total \\
\hline Curative surgery & $67(39.6 \%)$ & $205(49.5 \%)$ & $272(46.7 \%)$ \\
Lobectomy & $49(29.0 \%)$ & $150(36.2 \%)$ & $199(34.1 \%)$ \\
Partial resection of lung & $16(9.5 \%)$ & $43(10.4 \%)$ & $59(10.1 \%)$ \\
Pneumonectomy & $2(1.2 \%)$ & $12(2.9 \%)$ & $14(2.4 \%)$ \\
SABR & $22(13.0 \%)$ & $42(10.1 \%)$ & $64(11.0 \%)$ \\
Radical radiotherapy & $23(13.6 \%)$ & $44(10.6 \%)$ & $67(11.5 \%)$ \\
Curative chemo/radiotherapy & $7(4.1 \%)$ & $9(2.2 \%)$ & $16(2.7 \%)$ \\
Palliative radiotherapy & $14(8.3 \%)$ & $19(4.6 \%)$ & $33(5.7 \%)$ \\
Palliative chemotherapy & $4(2.4 \%)$ & $10(2.4 \%)$ & $14(2.4 \%)$ \\
Supportive care & $32(18.9 \%)$ & $85(20.5 \%)$ & $117(20.1 \%)$ \\
Total & 169 & 414 & 583 \\
\hline
\end{tabular}

included significant comorbidities in 37 (22.6\%) patients, 24 (14.6\%) poor lung function, 24 (14.6\%) poor ECOG status, 19 (11.6\%) high risk of surgical complications, 16 (9.8\%) patient refusal and 43 (26.2\%) unrecorded.

The logistic regression model showed that age, year of diagnosis, cancer stage, cancer cell type, FEV1 and ECOG status had an impact on the likelihood of having curative treatment (Table 3). Patients who were younger, were diagnosed in more recent years, had stage I disease, had NSCLC, had FEV1 of $80 \%+$, and had an ECOG score of 0 were more likely to receive curative treatment. Amongst those who received curative treatments, younger patients were more likely to have surgery as the primary treatment (odds ratio: 0.91, 95\%:0.87-0.95). Current smokers and ex-smokers were less likely to have surgery and more likely to be treated with radiotherapy and chemotherapy than people who never smoked (respective odds ratio: 0.11 (95\% Confidence interval (CI): 0.02-0.46); 0.23 (95\% CI: 0.06-0.89)). Patients who had NSCLC, had FEV1 of $80 \%+$, and had an ECOG score of 0 were more likely to undergo surgery. After adjustment for other factors we did not find a difference in access to curative treatment and curative surgery between Māori and non-Māori patients (respective odds ratio: 0.80 (95\% CI: 0.46-1.38); 1.03 (95\% CI: 0.53-2.00)).

There were 217 deaths (37.3\%) in this cohort with a median follow-up time of 27 months and a mean followup time 34 months. Outcomes in patients with stage I and II lung cancer varied depending on the treatment received (Fig. 1). Those who were treated with surgery had a 2-year survival of $87.8 \%$ (95\% CI: $83.8-91.8 \%$ ) and 5 -year survival of $69.6 \%$ (95\% CI: $63.2-76.0 \%$ ). SABR has only been available in the region since mid 2015 but outcomes are similar to surgery in the first 2 years post treatment (2-year survival: 85.2, 95\% CI: 75.8-94.7\%, $\log$-rank test $p$-value $=0.556$ ). Prior to the use of SABR, some patients were offered radiotherapy with curative intent and in this group of patients 2-year survival is only $65.3 \%$ (95\% CI: 53.1-77.4\%) and 5-year survival was $50 \%$. Patients offered palliative treatment only had a 2 year survival of $45.0 \%$ (95\% CI: 37.0-53.0\%) and 5-year survival of $31.8 \%$ (95\% CI: $23.9-39.6 \%$ ).

Māori patients had a similar survival to non-Mãori patients (Fig. 2, Log-rank test p-value $=0.091$ ). The 2-year and 5-year survival for Mãori patients was 69.4\% (95\% CI: $62.2-76.7 \%)$ and $47.1 \%$ (95\% CI: 37.8-56.4\%), compared to $73.5 \%$ (95\% CI: $69.1-77.9 \%)$ and 59.3\% (95\% CI: 53.9-64.8\%) for non-Māori patients.

The hazard ratio (Table 4) of all-cause mortality for Māori patients compared to non-Māori patients was 1.25 (95\% CI: $0.92-1.69$, p-value $=0.150)$. SABR has equivalent effect on survival compared to curative surgery (hazard ratio: $0.77,95 \%$ CI: $0.37-1.61$ ). The all-cause survival for stage I and II lung cancer patients has improved over time (hazard ratio: 0.94, 95\% CI: 0.87-1.00).

\section{Discussion}

We found that $71.9 \%$ of early stage lung cancer patients in our region were treated with potentially curative treatment. The commonest form of treatment was surgery. Thus in the Midlands Region a total of 272/3331 $(8.2 \%)$ of lung cancer patients were treated with curative surgery. This low rate of surgical treatment is similar to that found in the UK but lower than the rate reported in Australia and some European countries [11, 12]. While the advent of SABR has coincided with an increasing proportion of early stage patients being offered curative treatment, significant improvement will only be achieved when the proportion of patients with early stage disease at diagnosis is increased. This can either be achieved through greater awareness of symptoms of lung cancer e.g. through social media campaign [13] and through the introduction of lung cancer screening $[14,15]$.

We have shown that there are a number of reasons why patients do not receive curative treatment. Overall, less than half of patients with stage I and II disease in our region 272/583 (46.7\%) were treated with surgery. This figure has not improved from the findings in a similar New Zealand study in 2004 which reported a surgery rate of $56 \%$ of stage I and II NSCLC [7]. Another $147 / 583(25.2 \%)$ of patients in our study were treated with alternative potentially curative treatment while 164/ $583(28.1 \%)$ were treated with palliative care only. Patients with stage I and II NSCLC receiving palliative care were older than those who had curative treatment (mean age of 73 years vs 68 years). Other reasons included cancer stage -(stage II cases were less likely to be treated curatively than stage I), cancer cell type (small cell tumours were less likely to be treated than NSCLC), and those with COPD or poor respiratory function who were less likely to receive surgery or curative treatment as were those with a poor ECOG status. These findings are 
Table 3 Adjusted odds ratios from logistic regression model

\begin{tabular}{|c|c|c|c|c|c|c|}
\hline \multirow[t]{2}{*}{ Subgroup } & \multicolumn{3}{|c|}{ Having curative treatment vs no curative treatment } & \multicolumn{3}{|c|}{ Having surgery vs other curative treatment } \\
\hline & Odds ratio & $95 \% \mathrm{Cl}$ & $p$-value & Odds ratio & $95 \% \mathrm{Cl}$ & $p$-value \\
\hline \multicolumn{7}{|l|}{ Sex } \\
\hline Female & Ref & & & Ref & & \\
\hline Male & 0.85 & $(0.51-1.41)$ & 0.536 & 1.26 & $(0.70-2.29)$ & 0.446 \\
\hline \multicolumn{7}{|l|}{ Ethnicity } \\
\hline Māori & 0.80 & $(0.46-1.38)$ & 0.424 & 1.03 & $(0.53-2.00)$ & 0.932 \\
\hline Non-Māori & Ref & & & Ref & & \\
\hline Age (Continuous) & 0.92 & $(0.89-0.95)$ & $<0.001$ & 0.91 & $(0.87-0.95)$ & $<0.001$ \\
\hline \multicolumn{7}{|l|}{ Smoking status } \\
\hline Current smoker & 0.40 & $(0.12-1.38)$ & 0.149 & 0.11 & $(0.02-0.46)$ & 0.003 \\
\hline Ex-smoker & 0.49 & $(0.15-1.57)$ & 0.229 & 0.23 & $(0.06-0.89)$ & 0.033 \\
\hline Never smoked & Ref & & & Ref & & \\
\hline \multicolumn{7}{|l|}{ Charlson Comorbidity } \\
\hline 0 & Ref & & & Ref & & \\
\hline 1 & 0.82 & $(0.36-1.87)$ & 0.644 & 0.43 & $(0.17-1.11)$ & 0.080 \\
\hline 2 & 1.06 & $(0.45-2.50)$ & 0.902 & 0.35 & $(0.13-0.93)$ & 0.035 \\
\hline 3 & 0.93 & $(0.34-2.54)$ & 0.894 & 0.20 & $(0.06-0.73)$ & 0.015 \\
\hline $4+$ & 0.55 & $(0.15-2.02)$ & 0.365 & 0.10 & $(0.02-0.56)$ & 0.009 \\
\hline Year of diagnosis (Continuous) & 1.15 & $(1.03-1.28)$ & 0.015 & 0.75 & $(0.65-0.86)$ & $<0.001$ \\
\hline \multicolumn{7}{|l|}{ Stage } \\
\hline । & Ref & & & Ref & & \\
\hline$\|$ & 0.29 & $(0.17-0.48)$ & $<0.001$ & 0.58 & $(0.31-1.08)$ & 0.088 \\
\hline \multicolumn{7}{|l|}{ Cell type } \\
\hline NSCLC & Ref & & & Ref & & \\
\hline Others & 0.29 & $(0.17-0.51)$ & $<0.001$ & 0.08 & $(0.03-0.23)$ & $<0.001$ \\
\hline \multicolumn{7}{|l|}{ FEV1 } \\
\hline$<50 \%$ & 0.35 & $(0.16-0.77)$ & 0.009 & 0.04 & $(0.01-0.12)$ & $<0.001$ \\
\hline $50 \% \sim 80 \%$ & 0.70 & $(0.36-\backslash 1.38)$ & 0.304 & 0.42 & $(0.20-0.85)$ & 0.016 \\
\hline $80 \%+$ & Ref & & & Ref & & \\
\hline \multicolumn{7}{|l|}{ ECOG } \\
\hline 0 & Ref & & & Ref & & \\
\hline 1 & 0.52 & $(0.26-1.02)$ & 0.056 & 0.57 & $(0.30-1.09)$ & 0.091 \\
\hline $2+$ & 0.13 & $(0.06-0.26)$ & $<0.001$ & 0.14 & $(0.05-0.40)$ & $<0.001$ \\
\hline
\end{tabular}

similar to the findings from a Danish study [16] of stage I lung cancer and the historical New Zealand study [7].

SCLC proliferates more rapidly and has a high propensity to metastasise. Most cases will present with locally advanced or metastatic disease. On rare occasions, patients are identified with small cell lung cancer (SCLC) histology but with early stage disease potentially suitable for resection [17]. Overall our cohort had 440/3331 (13\%) small cell lung cancers. There were only 14 small cell lung cancer cases in our group of stage I and II diseases, and only one had curative surgery. In a large cohort of 45,848 patients with SCLC only $1 \%$ were treated surgically [18]. The
5 -year survival in this cohort from the turn of the century was only $31 \%$ and the HR compared with NSCLC was 1.47 [18]. Our findings suggest that surgical intervention for SCLC is a rare event, partly because few cases present with early stage disease and other treatment modalities are more likely to be taken up.

Our study also shows that patients who identify as Māori are less likely to receive curative surgical resection of stage I and II lung cancer than those who do not identify as Māori. This finding was based on the unadjusted analysis, and the difference disappeared after adjustment for other factors. This could suggest that the New Zealand 


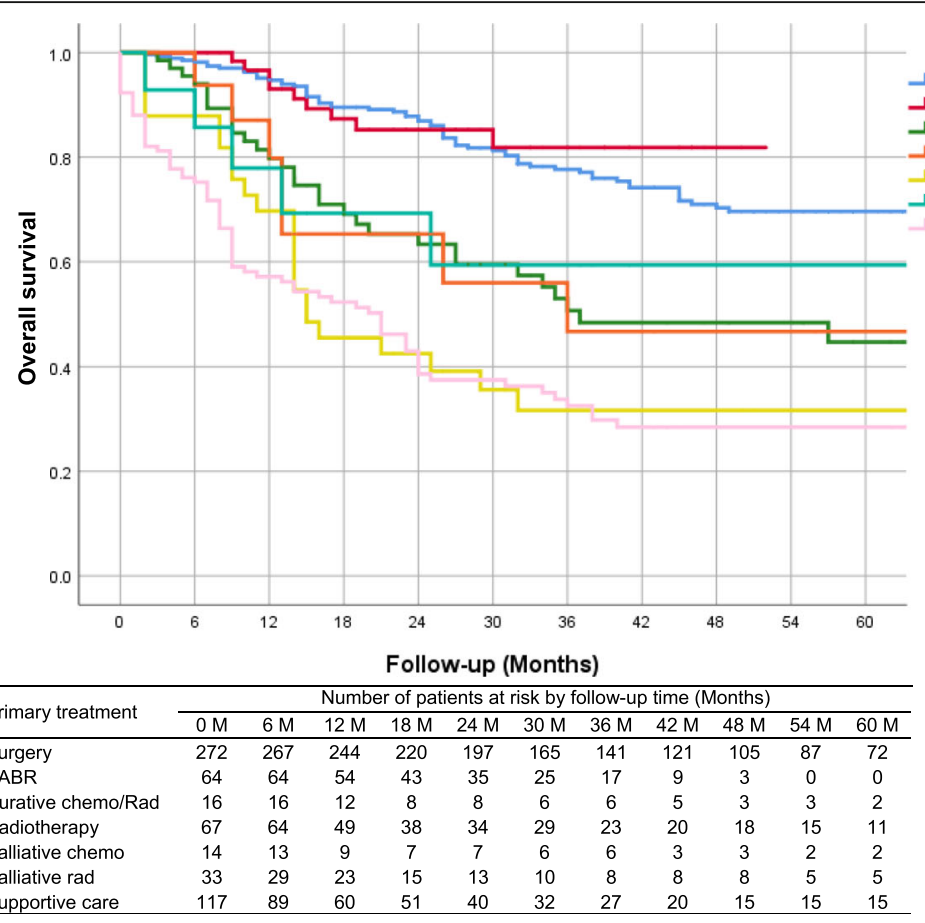

Fig. 1 All-cause survival by treatment option

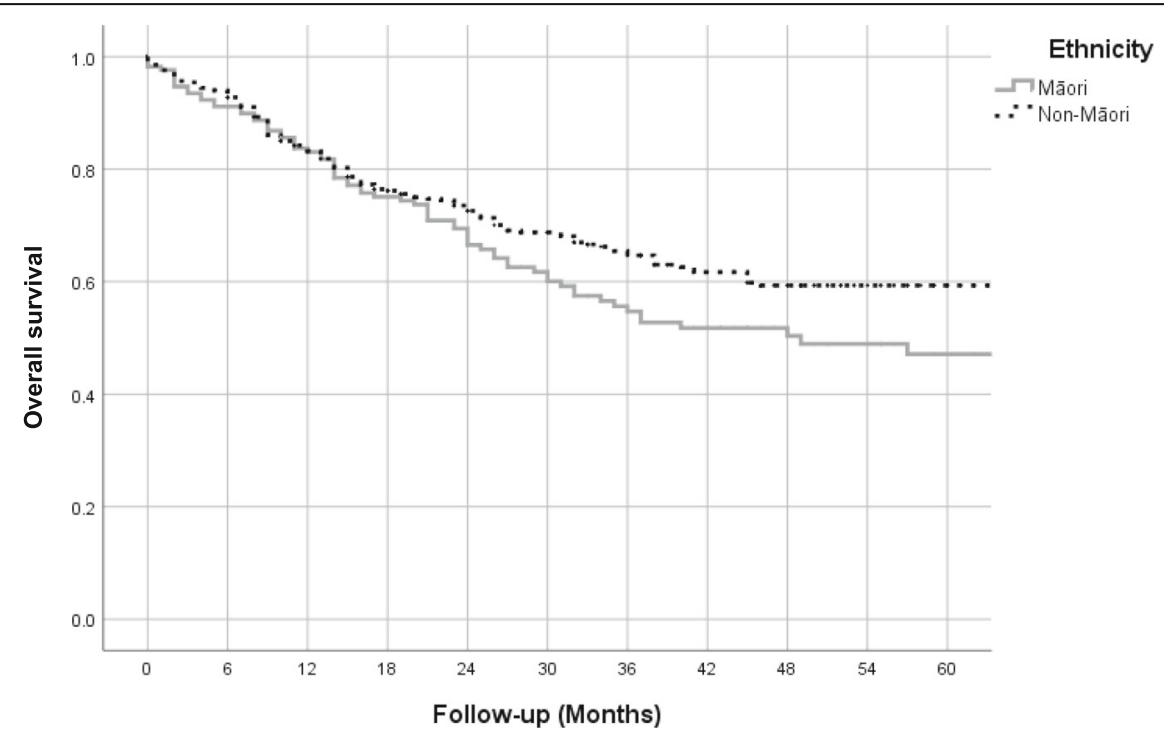

\begin{tabular}{lccccccccccc}
\hline \multirow{2}{*}{ Primary treatment } & \multicolumn{10}{c}{ Number of patients at risk by follow-up time (Months) } \\
\cline { 2 - 13 } & $0 \mathrm{M}$ & $6 \mathrm{M}$ & $12 \mathrm{M}$ & $18 \mathrm{M}$ & $24 \mathrm{M}$ & $30 \mathrm{M}$ & $36 \mathrm{M}$ & $42 \mathrm{M}$ & $48 \mathrm{M}$ & $54 \mathrm{M}$ & $60 \mathrm{M}$ \\
\hline Māori & 169 & 154 & 129 & 109 & 95 & 74 & 59 & 51 & 37 & 30 & 24 \\
Non-Māori & 414 & 388 & 322 & 273 & 239 & 199 & 169 & 135 & 118 & 97 & 83 \\
\hline
\end{tabular}

Fig. 2 All-cause survival between Māori and non-Māori 
Table 4 Adjusted hazard ratio for overall survival from Cox proportional hazard model

\begin{tabular}{|c|c|c|c|}
\hline Factors & $\begin{array}{l}\text { Hazard } \\
\text { ratio }\end{array}$ & $\begin{array}{l}95 \% \mathrm{Cl} \text { of hazard } \\
\text { ratio }\end{array}$ & $P$-value \\
\hline \multicolumn{4}{|l|}{ Sex } \\
\hline Female & Ref & & \\
\hline Male & 1.21 & $(0.91-1.62)$ & 0.195 \\
\hline \multicolumn{4}{|l|}{ Ethnicity } \\
\hline Māori & 1.25 & $(0.92-1.69)$ & 0.151 \\
\hline Non-Māori & Ref & & \\
\hline Age (Continuous) & 1.01 & $(0.99-1.03)$ & 0.172 \\
\hline \multicolumn{4}{|l|}{ Charlson Comorbidity } \\
\hline 0 & Ref & & \\
\hline 1 & 1.10 & $(0.70-1.75)$ & 0.673 \\
\hline 2 & 1.07 & $(0.66-1.73)$ & 0.794 \\
\hline 3 & 1.02 & $(0.55-1.86)$ & 0.959 \\
\hline $4+$ & 1.19 & $(0.58-2.44)$ & 0.640 \\
\hline \multicolumn{4}{|l|}{ Smoking status } \\
\hline Current smoker & 2.51 & $(1.06-5.94)$ & 0.037 \\
\hline Ex-smoker & 2.24 & $(0.96-5.22)$ & 0.061 \\
\hline Never smoked & Ref & & \\
\hline Year of diagnosis (Continuous) & 0.94 & $(0.87-1.00)$ & 0.068 \\
\hline \multicolumn{4}{|l|}{ Stage } \\
\hline I & Ref & & \\
\hline$\|$ & 1.35 & $(1.02-1.80)$ & 0.039 \\
\hline \multicolumn{4}{|l|}{ Primary treatment } \\
\hline Curative surgery & Ref & & \\
\hline SABR & 0.77 & $(0.37-1.61)$ & 0.486 \\
\hline Radiotherapy & 1.94 & $(1.23-3.07)$ & 0.005 \\
\hline Curative chemo/Rad & 1.80 & $(0.80-4.03)$ & 0.153 \\
\hline Palliative rad & 2.89 & $(1.72-4.85)$ & $<0.001$ \\
\hline Palliative chemo & 1.69 & $(0.66-4.32)$ & 0.270 \\
\hline Supportive care & 3.35 & $(2.26-4.96)$ & $<0.001$ \\
\hline
\end{tabular}

healthcare system is ensuring equity of access to curative surgical resection for patients. Māori presenting with early stage disease are younger than non-Māori, and more likely to have COPD, be a current smoker, have an FEV1 less than $50 \%$ and have small cell histology. Māori generally have lower socioeconomic status which is associated with poor surviva $[19,20]$. After adjustment for these factors it appears that Māori are not less likely to receive curative treatment (odds ratio $0.80,95 \%$ CI $0.46-1.38$ ) or surgery (odds ratio 1.03, 95\% CI: 0.53-2.00). It maybe this finding is a Type 2 error and if we had a bigger sample then potentially we might show a difference. This means that we need to continue to monitor access to curative treatments for Māori if we are to reduce the inequities in outcomes that we know are present $[7,21]$.
Our findings show that the all-cause survival from surgery in this group of patients are $85 \%$ at 2 years and $70 \%$ at 5 years. This is similar to the survival reported in a 2004 study where the 2 -year survival was $81 \%$ [7]. This supports the assertion that early stage lung cancer can be "cured" [22]. Indeed if we look just at the 199 NSCLC patients treated with lobectomy we find the 5-year survival is over $70 \%$ which is comparable with the findings from studies in major centres in the USA [22].

Patients with stage I and II NSCLC treated with SABR have comparable outcomes to those treated with surgery. This is despite the finding that those treated with curative intent with SABR tended to have additional risk factors including older age, higher ECOG status score, more comorbidities and more smokers. The numbers of patients treated with SABR is relatively small and further follow up of a greater number of patients is needed to confirm this finding but the initial results are very encouraging. A systematic review [23] reported that the overall and cancer-specific survival between SABR and lobectomy for stage I NSCLC were similar after 1-year follow-up, but lobectomy appeared to have more favourable outcomes after 3-year and 5-year follow-up. However, this systematic review only included one randomised clinical trial [24] and the other six included studies were cohort studies which may have been subject to bias [25-30].

Outcomes in patients managed with palliative care are relatively poor where only $30 \%$ of palliative patients with Stage I and II disease are surviving 5 years. Many of these patients are older and have significant comorbidities which impact on overall survival. The small number of patients offered palliative chemotherapy appear to be doing better with a 2-year survival of $60 \%$. However, overall survival in this group of patients managed with supportive/palliative care is higher than previous reports. Stevens et al. [7] only showed $20 \%$ survival with 2 years follow-up, while our study has shown similar improvement year by year during the study period.

One of the strengths of our study is that it was based on the comprehensive lung cancer register, with relatively complete data on patient demographics, tumour characteristics and treatment. The limitations of this study included the small number of patients and short follow-up time in some treatment group, e.g. SABR. Also as an observation study, this study is prone to selection bias.

\section{Conclusions}

The majority of patients with stage I and II lung cancer are managed with potential curative treatment - mainly surgery and increasingly SABR. After adjustment for key variables such as smoking, comorbidities and lung function status, the likelihood of Māori patients having 
curative treatment was similar to non-Māori. This suggest that outcomes for Māori patients can be improved by addressing smoking and the management of comorbidities. While the outcomes of those being diagnosed with stage I and II disease and receiving treatment is positive with $70 \%$ surviving 5 years, the next target is to substantially increase the population of lung cancer patients diagnosed with early stage disease.

\section{Abbreviations}

Cl: Confidence interval; COPD: Chronic obstructive pulmonary disease; DHB: District Health Boards; ECOG: Eastern Cooperative Oncology Group; FEV1: Forced Expiratory Volume; MDM: Multidisciplinary meeting; NSCLC: Non-small cell lung cancer; NZCR: New Zealand Cancer Registry; SABR: Stereotactic ablative body radiotherapy; SCLC: Small cell lung cancer

\section{Acknowledgements}

The Midland Cancer Register is maintained by the Midland Cancer Network and this study has been supported by grants from the New Zealand Cancer Society, the Waikato Medical Research Foundation and the Health Research Council of New Zealand (grant number: 17/438). The funders did not play any role in the research design, data analyses or results interpretation.

\section{Authors' contributions}

RL, PC, JW and DA conceived of and designed the study. LB, LM and KM collected the data. $\mathrm{CL}$ and $\mathrm{LB}$ did the data cleaning and analyses. $\mathrm{RL}, \mathrm{CL}, \mathrm{RK}$, CG, LC and JK were involved in the interpretation of data. All the authors were involved in the drafting of the manuscript and the critical revisions. All the authors approved the submitted version and have agreed both to be personally accountable for the author's own contributions and to ensure that questions related to the accuracy or integrity of any part of the work, even ones in which the author was not personally involved, are appropriately investigated, resolved, and the resolution documented in the literature.

\section{Funding}

Funding has been received from the New Zealand Cancer Society, the Waikato Medical Research Foundation and the Health Research Council of New Zealand (grant number: 17/438). While the overall study has been peer reviewed by the funding bodies, they have had no role in the design of the study and collection, analysis, and interpretation of data and or writing the manuscript.

\section{Availability of data and materials}

The datasets generated and/or analysed during the current study are not publicly available due the confidentiality of patient data but are available from the corresponding author on reasonable request.

\section{Ethics approval and consent to participate}

Ethical approval for the study was granted through the Southern Health and Disability Ethics Committee (HDEC reference: 16/STH/167). As this was a retrospective observational study using anonymised data, individual patient consent was not deemed a requirement by HDEC.

\section{Consent for publication}

Not applicable.

\section{Competing interests}

The authors declare that they have no competing interests.

\section{Author details}

'Waikato Medical Research Centre, The University of Waikato, Level 3 Hockin building, Waikato Hospital, Hamilton 3240, New Zealand. ${ }^{2}$ Strategy and Funding, Waikato District Health Board, Hamilton, New Zealand. ${ }^{3}$ Midland Cancer Network, Hamilton, New Zealand. ${ }^{4}$ Taupua Waiora Research Centre, Auckland University of Technology, Auckland, New Zealand. ${ }^{5}$ Respiratory Department, Waikato District Health Board, Hamilton, New Zealand. ${ }^{6}$ Waikato Cardiothoracic Unit, Waikato District Health Board, Hamilton, New Zealand. ${ }^{7}$ Radiation Oncology, Waikato District Health Board, Hamilton, New Zealand. ${ }^{8}$ Respiratory Department, Lake District Health Board, Rotorua, New Zealand.
Received: 29 October 2019 Accepted: 27 January 2020

Published online: 10 February 2020

\section{References}

1. Ministry of Health. Cancer: new registrations and deaths 2013. Wellington: Ministry of Health; 2016.

2. National Lung Cancer Working Group. Standards of service provision for lung Cancer patients in New Zealand. Wellington: Ministry of Health; 2011.

3. Lawrenson R, Lao C, Brown L, et al. Characteristics of lung cancers and accuracy and completeness of registration in the New Zealand Cancer Registry. N Z Med J. 2018;131(1479):13-23 published Online First: 2018/07/27.

4. Verstegen NE, Oosterhuis JWA, Palma DA, et al. Stage I-II non-small-cell lung cancer treated usingeither stereotactic ablative radiotherapy (SABR) orlobectomy by video-assisted thoracoscopic surgery(VATS): outcomes of a propensity score-matchedanalysis. Ann Oncol. 2013;24(6):1543-8. https://doi. org/10.1093/annonc/mdt026.

5. Møller H, Coupland VH, Tataru D, et al. Geographical variations in the use of cancer treatments are associated with survival of lung cancer patients. Thorax. 2018;73(6):530-7. https://doi.org/10.1136/thoraxjnl-2017-210710.

6. Mitchell PL, Thursfield VJ, Ball DL, et al. Lung cancer in Victoria: are we making progress? Med J Aust. 2013;199(10):674-9 published Online First: 2013/11/19

7. Stevens W, Stevens G, Kolbe J, et al. Management of stages I and II nonsmall-cell lung cancer in a New Zealand study: divergence from international practice and recommendations. Int Med J. 2008;38(1):758-68 https://doi.org/10.1111/j.1445-5994.2007.01523.x published Online First: 2008/02/27.

8. Stevens W, Stevens G, Kolbe J, et al. Ethnic Differences in the Management of Lung Cancer in New Zealand. J Thoracic Oncol. 2008;3(3):237-44. https:// doi.org/10.1097/JTO.0b013e3181653d08.

9. Malalasekera A, Tan CSY, Phan V, et al. Eastern Cooperative Oncology Group score: Agreement between non-small-cell lung cancer patients and their oncologists and clinical implications. Can Treat Comm. 2016;5:17-21. https://doi.org/10.1016/j.ctrc.2015.11.009.

10. Quan H, Li B, Couris CM, et al. Updating and validating the Charlson comorbidity index and score for risk adjustment in hospital discharge abstracts using data from 6 countries. Am J Epidemiol. 2011;173(6):676-82. https://doi.org/10.1093/aje/kwq433.

11. Imperatori A, Harrison RN, Leitch DN, et al. Lung cancer in Teesside (UK) and Varese (Italy): a comparison of management and survival. Thorax. 2006; 61(3):232-9. https://doi.org/10.1136/thx.2005.040477 published Online First: 2005/11/15.

12. Currow $D$, You H, Aranda $S$, et al. What factors are predictive of surgical resection and survival from localised non-small cell lung cancer? Med J Aust. 2014;201(8):475-80.

13. Kennedy MPT, Cheyne L, Darby M, et al. Lung cancer stage-shift following a symptom awareness campaign. Thorax. 2018;73(12):1128-36. https://doi.org/ 10.1136/thoraxinl-2018-211842.

14. Horeweg N, van der Aalst CM, Thunnissen E, et al. Characteristics of lung cancers detected by computer tomography screening in the randomized NELSON trial. Am J Respir Crit Care Med. 2013;187(8):848-54. https://doi.org/ 10.1164/rccm.201209-16510C published Online First: 2013/01/26.

15. Reduced Lung-Cancer Mortality with Low-Dose Computed Tomographic Screening. New England Journal of Medicine 2011;365(5):395-409. doi: https://doi.org/10.1056/NEJMoa1 102873

16. Christensen NL, Dalton S, Ravn J, et al. Treatment, no treatment and early death in Danish stage I lung cancer patients. Lung Cancer. 2019;131:1-5. https://doi.org/10.1016/j.lungcan.2019.03.007.

17. Baldwin DR, White B, Schmidt-Hansen M, et al. Diagnosis and treatment of lung cancer. summary of updated NICE guidance. BMJ (Clinical research ed). 2011;342: d2110. https:/doi.org/10.1136/bmj.d2110 published Online First: 2011/04/29.

18. Luchtenborg M, Riaz SP, Lim E, et al. Survival of patients with small cell lung cancer undergoing lung resection in England, 1998-2009. Thorax. 2014; 69(3):269-73. https://doi.org/10.1136/thoraxjnl-2013-203884 published Online First: 2013/11/01.

19. Blakely T, Tobias M, Atkinson J, et al. Tracking disparity: trends in ethnic and socioeconomic inequalities in mortality, 1981-2004. Ministry of Health: Wellington; 2007.

20. Tin Tin S, Elwood JM, Brown C, et al. Ethnic disparities in breast cancer survival in New Zealand: which factors contribute? BMC Cancer. 2018;18(1): 58. https://doi.org/10.1186/s12885-017-3797-0. 
21. Sutherland TJ, Aitken D. Ethnic and socioeconomic inequalities in lung cancer in a New Zealand population. Respirology (Carlton, Vic). 2008;13(4): 590-3. https://doi.org/10.1111/j.1440-1843.2008.01301.x published Online First: 2008/05/23.

22. Blandin Knight $\mathrm{S}$, Crosbie PA, Balata $\mathrm{H}$, et al. Progress and prospects of early detection in lung cancer. Open Biol. 2017;7(9):170070. https://doi.org/10. 1098/rsob.170070

23. Wang $S$, Wang $X$, Zhou $Q$, et al. Stereotactic ablative radiotherapy versus lobectomy for stage I non-small cell lung cancer: A systematic review. Thorac Can. 2018;9(3):337-47. https://doi.org/10.1111/1759-7714.12574 published Online First: 2018/01/13.

24. Chang JY, Senan S, Paul MA, et al. Stereotactic ablative radiotherapy versus lobectomy for operable stage I non-small-cell lung cancer: a pooled analysis of two randomised trials. Lancet Oncol. 2015;16(6):630-7. https://doi.org/10. 1016/s1470-2045(15)70168-3 published Online First: 2015/05/20.

25. Crabtree TD, Puri V, Robinson C, et al. Analysis of first recurrence and survival in patients with stage I non-small cell lung cancer treated with surgical resection or stereotactic radiation therapy. J Thorac Cardiovasc Surg. 2014;147(4):1183-91. https://doi.org/10.1016/j.jtcvs.2013.11.057 published Online First: 2014/02/11]. discussion 91-2.

26. Hamaji M, Chen F, Matsuo Y, et al. Video-assisted thoracoscopic lobectomy versus stereotactic radiotherapy for stage I lung cancer. Ann Thorac Surg. 2015;99(4):1122-9. https://doi.org/10.1016/j.athoracsur.2014.11.009 published Online First: 2015/02/11.

27. Mokhles S, Verstegen N, Maat AP, et al. Comparison of clinical outcome of stage I non-small cell lung cancer treated surgically or with stereotactic radiotherapy: results from propensity score analysis. Lung Cancer. 2015;87(3): 283-9. https://doi.org/10.1016/j.lungcan.2015.01.005 published Online First: 2015/01/28

28. Palma D, Visser O, Lagerwaard FJ, et al. Treatment of stage I NSCLC in elderly patients: a population-based matched-pair comparison of stereotactic radiotherapy versus surgery. Radiother Oncol. 2011;101(2):240-4. https://doi. org/10.1016/j.radonc.2011.06.029 published Online First: 2011/07/22

29. Robinson CG, DeWees TA, El Naqa IM, et al. Patterns of failure after stereotactic body radiation therapy or lobar resection for clinical stage I non-small-cell lung cancer. J Thorac Oncol. 2013;8(2):192-201. https://doi. org/10.1097/JTO.0b013e31827ce361 published Online First: 2013/01/05.

30. Varlotto J, Fakiris A, Flickinger J, et al. Matched-pair and propensity score comparisons of outcomes of patients with clinical stage I non-small cell lung cancer treated with resection or stereotactic radiosurgery. Cancer. 2013;119(15):2683-91. https://doi.org/10.1002/cncr.28100 published Online First: 2013/04/23.

\section{Publisher's Note}

Springer Nature remains neutral with regard to jurisdictional claims in published maps and institutional affiliations.

Ready to submit your research? Choose BMC and benefit from:

- fast, convenient online submission

- thorough peer review by experienced researchers in your field

- rapid publication on acceptance

- support for research data, including large and complex data types

- gold Open Access which fosters wider collaboration and increased citations

- maximum visibility for your research: over $100 \mathrm{M}$ website views per year

At BMC, research is always in progress.

Learn more biomedcentral.com/submissions 